\title{
Postpartum dönemde cinsel sağlık ve danıșmanlık: BETTER modeli kullanımı
}

\author{
Sexual health and counseling in the postpartum period: \\ Using the BETTER model
}

\author{
Seda Çetin Avcl®, Zeynep Dașıkan²®
}

\section{öz}

Cinsellik doğum öncesi başlayıp ömür boyu devam eden birçok faktörden etkilenen ve şekillenen kompleks bir kavramdır. Cinsellik, bireyin gelişim dönemlerinden ve yaşamındaki değişik olaylardan sürekli olarak etkilenerek değişim gösterebilmektedir. Postpartum dönemdeki kadınlarda meydana gelen değişiklikler, değişen roller ve sorumluluklar kadınların cinsel yaşamlarını, cinsel istek ve memnuniyetlerini olumsuz etkileyebilmektedir. Cinselliğin değerlendirilmesi, cinsel eğitim ve danışmanlık rutin postpartum bakımın bir parçası olmalı ve bu konuya önem verilmelidir. Cinselliğin değerlendirilmesinde model kullanımı anamnez sürecini kolaylaştırmaktadır. Ayrıca sağlık personelinin cinselliği daha rahat konuşabilmesine yardımcı olmaktadır. Postpartum cinsel sağlığın değerlendirilmesi ve iyileştirilmesinde PLISSIT (Permission (P), Limited Information (LI), Specific Suggestions (SS), Intensive Therapy (IT)), BETTER (Bringing up the topic (B), Explain you are concerned with quality-of-life issues, including sexuality (E), Telling patients that resources will be found to adres their concerns (T), Timing of intervention $(T)$, Educate patients about the side effects of their cancer treatments (E), Recording (R)) REDI, Levine gibi modellere dayalı cinsel sağlık eğitimlerin ve danışmanlıkların etkili olduğu görülmektedir. Bu nedenle sağlık profesyonelleri postpartum bakımda bu modellerden birini kullanarak kadınların cinselliğini değerlendirmeli ve danışmanlık vermelidir. Yapılan son çalışmada postpartum cinsel sorunların ifade edilmesinde BETTER modelinin PLISSIT modeline kıyasla daha etkili olduğu bulunmuştur. Bu sonuca dayanarak da BETTER modeline dayalı danışmanlığın kullanımının arttırılması önerilir. Bu derlemenin amacı literatür doğrultusunda postpartum dönemde cinsel sağlık, cinsel danışmanlığı ele almak ve BETTER modeli kullanarak cinsel danışmanlık örneği oluşturmaktır.

Anahtar Kelimeler: BETTER modeli, cinsellik, danışmanlık, emzirme, postpartum dönem, anne sağlığı

'İzmir Katip Çelebi Üniversitesi Sağlık Bilimleri Fakültesi, Kadın Sağlığı ve Hastalıkları Anabilim Dalı, İmir, Türkiye

${ }^{2}$ Ege Üniversitesi Hemşirelik Fakültesi, Kadın Sağlığı ve Hastalıkları Anabilim Dalı, Izmir, Türkiye

\section{Yazısma Adresi/ Correspondence:}

Arş. Gör. Seda Çetin Avcı

İzmir Katip Çelebi Üniversitesi Sağlık Bilimleri Fakültesi, Çiğli Ana Yerleşke Merkezi

Ofisler, 1 Kat: 235620 Çiğli/İzmir, Türkiye

Tel. $\quad$ +905514064074

E-mail: sedactn13@gmail.com

Gelis/ Received: $\quad 03.04 .2021$

Kabul/ Accepted: 10.05 .2021

\section{ABSTRACT}

Sexuality is a complex concept that starts before birth and continues throughout life, and is affected and shaped by many factors. Sexuality can change by being constantly affected by the developmental periods and different events in the life of the individual. Changes in women in the postpartum period, changing roles and responsibilities can negatively affect women's sexual lives, sexual desire and satisfaction. Evaluation of sexuality, sexual education and counseling should be a part of routine postpartum care and this issue should be given importance. The use of a model in the evaluation of sexuality facilitates the anamnesis process. It also helps healthcare personnel to speak about sexuality more comfortably. Sexual health trainings and counseling based on PLISSIT (Permission (P), Limited Information (LI), Specific Suggestions (SS), Intensive Therapy (IT)), BETTER (Bringing up the topic (B), Explain you are concerned with quality-of-life issues, including sexuality (E), Telling patients that resources will be found to adres their concerns ( $T$ ), Timing of intervention (T), Educate patients about the side effects of their cancer treatments (E), Recording (R)), REDI, Levine models seem to be effective in evaluation and improving postpartum sexual health. For this reason, health professionals should evaluate women's sexuality and provide consultancy by using one of these models in postpartum care. In the last study, it was found that the BETTER model is more effective than the PLISSIT model in expressing postpartum sexual problems. Based on this result, the use of consultancy based on the BETTER model should be increased. The aim of this review is to address sexual health, sexual counseling in the postpartum period in line with the literatüre and create an example of sexual counseling using the BETTER model.

Keywords: BETTER model, sexuality, counseling, breastfeeding, postpartum period, women's health 
göre cinsel sağlık; "Sadece hastalık, fonksiyon bozukluğu veya sakatliğın olmaması değil, duygusal, zihinsel ve sosyal olarak cinsellikle ilgili iyilik halidir" şeklinde tanımlanmıştır. ${ }^{[4]} \mathrm{Bu}$ kavramın çok boyutlu ve mahrem yönünün olması, bireysel ve kültürel değerlerden çok fazla etkilenmesi nedeniyle anlaşılması oldukça zordur. Oysa cinsellik doğumdan ölüme kadar insan yaşamında yer almakta ve bireyin gelişim dönemlerinden ya da yaşamındaki değişik olaylardan sürekli olarak etkilenerek değişim gösterebilmektedir. ${ }^{\left[{ }^{[}\right]}$

Gebelik döneminde meydana gelen fizyolojik ve psikolojik değişimler göz önüne alındığında, gebe kişilerin ve eşlerinin cinsel yaşamlarında değişiklik olması beklenen bir durumdur. Gebelikte cinsel aktivitede azalma yaygın olmakla birlikte çoğu toplumda gebe kadınlar aseksüel olarak görülmekte ve kadınların gebelikte cinsellik ile ilgili mitleri bulunmaktadır. ${ }^{[6]}$ Buna ek olarak, postpartum dönem de kadınlar için yeni bir dönem olup kadınların uyum sağlamaya çalıştığı bir periyottur. $\mathrm{Bu}$ dönemde kadının vücudunda meydana gelen anatomik, fizyolojik ve hormonal değişiklikler kadının cinsel fonksiyonlarında da değişikliğe neden olmaktadır. Kadınların yaşadığı disparoni, libido azalması, yorgunluk, uykusuzluk gibi sorunlar nedeniyle cinsel aktivitede azalma olmakla birlikte bazı kadınlar ya çok erken ya da çok geç zamanda cinsel aktiviteye başlamaktadır. ${ }^{[7,8]}$

Bundan dolayı hem gebelik hem postpartum dönem cinsellik açısından birtakım değişimlerin yaşandığı dönemler olup bu değişimler sonucunda kadınlarda bilgi açlığı oluşmaktadır. Fakat gebelik ve postpartum dönemde kadınlar cinselliği, yaşadıkları sorunları ve çözüm arayışlarını sağlık profesyonellerine anlatmaktan kaçınmaktadırlar. Aynı zamanda sağlık profesyonelleri de postpartum izlemlerde çoğu zaman cinselliği sorgulamayı ve danışmanlık yapmayı ihmal edebilmektedir. ${ }^{[9,10]}$ Oysaki rutin izlemler sayesinde kadınlara cinsel danışmanlık vererek doğru bilgilere, sorunlarının çözümlerine ulaşmalarını sağlamak için postpartum dönem bir firsattır.

Bu derlemenin amacı; literatür doğrultusunda postpartum dönemde cinsel sağlık ve cinsel danışmanlığı ele almak ve BETTER modeli kullanarak cinsel danışmanlık örneği oluşturmaktır.

\section{POSTPARTUM DÖNEMDE CINSEL SAĞLIK}

Postpartum dönem birçok değişikliklerin yaşandığı ve ele alınması gereken önemli bir dönemdir. Dünya Sağlık Örgütü’nün 2013 yılında yayınladığı anne ve yenidoğanın postpartum bakım kılavuzunda, doğum sonrası cinsel yaşam, kadının temel gereksinimlerinden biri olarak gösterilmekte ve bu dönemin cinsel sağlık ve fonksiyonları ile ilgili problemlerin zamanında tanımlanması, çözümlenmesi ve bu konuda bilgi ve danışmanlık hizmetlerinin verilmesi için bir fırsat olduğu bildirilmektedir. ${ }^{[11]}$ Literatürde yapılan çalışmalar postpartum dönemde cinsellikle ilgili sorunların yaygın olduğunu ve sorunların postpartum ilk üç ayda yoğunlaştığını göstermektedir. ${ }^{[3,12,13]}$ Postpartum ilk üç ayda kadınların \% 41 ila 87'si en az bir cinsel işlev bozukluğu şikayeti bildirmiştir. Cinsel sağlık sorunları doğumdan sonra 12 aya kadar veya daha uzun süre devam edebilmektedir. ${ }^{[3,9,12-15]}$ Ayrıca doğum şekli, müdahaleli vajinal doğum, perineal yaralanma durumu, doğum sayısı, emzirme ve önceden var olan cinsel işlev bozukluğu durumları postpartum cinsel işlev bozukluğu için risk faktörleri olarak belirtilmektedir. ${ }^{[14]}$ İnvolüsyon süreci, cinsel yanıt döngüsünü ve cinsel işlevleri etkilemektedir. Aynı zamanda bu dönemde yaşanan nöroendokrin değişiklikler de cinsel istek azlığııın başlıca nedenlerinden biridir. ${ }^{[3]}$ Postpartum dönemde kadının cinselliğe bakış açııında ve cinsel davranışlarında değişiklik olabilmektedir. ${ }^{[2,3]}$

Pardell-Dominguez ve ark.'nın (2021) postpartum primipar kadınlarda yaptığı fenomenolojik çalışmada; 'hazır hissetmeme', 'engelleyici faktörler', 'evde yeni gerçeklik', 'sosyo-kültürel faktörler' ve 'sağlık sistemi içinde klinisyen' olmak üzere beş ana tema ortaya çıkmıştır. Çalışmada kadınların çoğu postpartum dönemde libidosunun azaldığını, vücut imajının değiştiğini, kendini hazır hissetmeden cinsel aktiviteye başladığını ve partner desteğinin cinsel aktiviteye başlamada önemli olduğunu belirtmişlerdir. Kadınlar, cinselliği engelleyen faktörler olarak doğum sonrası ilk kırk gün ilişkiye girilmemesi inancı ve epizyotomi varlı̆ğ olduğunu vurgulamışlardır. Ayrıca, klinisyenlerle yapılan görüşmelerde postpartum cinsel sağlık tabu olarak tanımlanmıştır. ${ }^{[16]}$ Postpartum dönemde cinsel ilişkiye başlama zamanı kültürden kültüre değişiklik göstermektedir. Bazı toplumlarda kadınlar emzirme süresi boyunca ya da bebeğin ilk dişi çıkana kadar cinsel ilişkiye başlamamaktadırlar. Bunun aksine bazı kadınlar ise eşini tatmin edebilmek için normalden daha erken cinsel ilişkiye başlayabilmektedir. ${ }^{[17]}$ Ülkemizde geleneksel olarak postpartum dönemde cinsel ilişkiye başlama zamanı doğumdan altı hafta (40 gün) sonradır. ${ }^{[18]}$ Türkiye Nüfus ve Sağlık Araştırmaları Enstitüsü’nün (TNSA) 2018 verilerine göre postpartum kadınların \%77'si doğumdan sonra ilk iki ay içerisinde cinsel ilişkiden kaçınmaktadır. ${ }^{[19]}$ Bu veriye dayanarak ülkemizde kadınların 40 gün geleneğine uyduklarını söylemek mümkündür.

\section{POSTPARTUM CINSEL SAĞLIĞI ETKILLEYEN FAKTÖRLER}

Postpartum dönemde değişen roller ve sorumluluklar kadınların cinsel yaşamlarını, cinsel istek ve memnuniyetlerini olumsuz etkileyebilmekte, hatta korkuya neden olabilmektedir. ${ }^{[9,20,21]}$ Bu dönemde kadınların cinsel aktivitelerini 
etkileyen bazı durumlar bulunmaktadır. Bunlar; disparo$\mathrm{ni}^{[9,13,22]}$, libido azalmasi ${ }^{[23,24]}$, orgazm sorunlar ${ }^{[25,26]}$, olumsuz beden $\operatorname{alg}_{1 S 1}[24,27]$, yorgunluk ve uykusuzluk ${ }^{[23,24]}$, ev sorumluluklarr ${ }^{[24]}$ ve partnerini tatmin etme endişesidir. [12,28,29] $\mathrm{Bu}$ süreçte yaşanan fizyolojik ve psikolojik değişimlere ek olarak dini inanışlar, cinsel mitler ve sosyokültürel özellikler de postpartum dönemde cinsel yaşamın normale dönme sürecini etkileyebilmektedir. ${ }^{[3]}$

De Souza ve ark.'nın (2015) doğum şeklinin ve perineal yaralanmanın postpartum 6. ve 12. aylarda cinsel işlev üzerine etkisini belirlemek amacıyla yaptıkları prospektif kohort çalışmasında; doğum şekli ve perineal yaralanma varlığ fark etmeksizin postpartum 12. ayda cinsel işlevin erken gebelik dönemine döndüğü belirtilmiştir. ${ }^{[30]}$

Emzirmenin cinsel aktivite ve cinsel kalite üzerine etkisini belirlemek amaciyla Alp-Yılmaz ve ark.'nın (2019) yaptığı çalışmaya 161 emziren ve 176 emzirmeyen kadın dahil edilmiştir. Her iki gruptaki kadınlar, postpartum dönemde az sayıda cinsel ilişkide bulunduklarını ve disparoni şikâyeti yaşadıklarını bildirmişlerdir. Emzirmeyen kadınlarda emziren kadınlara göre cinsel doyum daha yüksek bulunmuştur. Emziren grupta cinsel istek ve cinsel ilişki sıklığının az olmasına rağmen, bildirilen cinsel yaşam kalitesi emziren ve emzirmeyen kadınlarda benzer bulunmuştur. ${ }^{[31]}$

İlk doğumunu yapan kadınlarda cinsel sağlık eğitiminin cinsel işlev ve postpartum cinsel ilişkiye yeniden başlama üzerindeki etkisini incelemek amacıyla Sheikhi ve ark.'nın (2020) yaptığı randomize kontrollü bir çalışmaya 94 primipar kadın dahil edilmiştir. Çalışmada müdahale grubuna doğumdan sonra $3-5$. günlerde, 10-14. günlerde ve 30-45. günlerde olmak üzere üç cinsel sağlık eğitimi yapılmış, kontrol grubuna ise rutin postpartum bakım uygulanmıştır. Müdahale grubuna yapılan cinsel sağlık eğitimi cinsel organların anatomisi, cinselliğin fizyolojisi, doğum sonrası değişiklikler, doğumdan sonra cinsel ilişkinin fizyolojik ve psikolojik yönleri, istenmeyen gebeliklerin önlenmesi ve emzirme döneminde cinsellik konularını içermektedir. Bu çalışma sonucuna göre müdahale grubundaki kadınlarda postpartum dönemde yapılan cinsel sağlık eğitimi cinsel işlevi iyileştirmiş, cinselliğe yeniden başlama zamanları bakımından ise iki grup arasında fark bulunmamıştır. Kadınların cinsel işlevini teşvik etmek için postpartum dönemde kadınlarda cinsel sağlı eğitim programlarının kullanılması önerilmiştir. ${ }^{[32]}$

Rahimi ve ark.'nın (2020) 150 nullipar kadında yaptığı çalışmada, doğum öncesi cinsellik, cinsel sağlık, pelvik kas egzersizlerini içeren bir eğitimin doğum sonrası evlilik doyumu düzeyine etkisini incelenmiştir. Müdahale grubuna doğum öncesi sekiz eğitimden oluşan bir eğitim paketi (cinsel sağllk ve cinsel konularla ilgili eğitim broşürü ve gebelik ve pelvik egzersizler hakkında bir eğitim CD’si) verilmiş, kontrol grubuna ise rutin doğum öncesi bakım uygulanmıştır. Evlilik memnuniyeti gebelik sırasında, müdahaleden önce ve doğumdan üç ay sonra ölçülmüştür. Müdahale öncesi ölçülen evlilik doyumlarında iki grup arasında bir fark bulunmaz iken eğitim sonrası müdahale grubunda doğum sonrası evlilik doyumu düzeyinde anlamlı bir farklılık saptanmıştır. Bu çalışma sonucunda doğum öncesi verilen cinsel eğitim paketi ile kadınlarda doğum sonrası evlilik memnuniyetinin arttırrlabileceği gösterilmiştir. ${ }^{[33]}$

\section{POSTPARTUM DÖNEM CINSEL DANIȘMANLIK}

Sağlık personeli ile kadınların daha fazla etkileşimde bulunduğu bir dönem olan postpartum dönem, postpartum cinsel sağlığın değerlendirilmesi için bir firsat yaratmaktadır. Ancak cinsellik sadece bireyler arasında tabu olarak görülmemekte, bazı sağlık profesyonelleri arasında da tabu olarak görülmektedir. Bu nedenle sağlık profesyoneli ile kadın arasında cinselliğin konuşulması, cinselliğin değerlendirilmesi ve cinsel danışmanlık yapmak oldukça güç olmaktadır. ${ }^{[3]}$ Oysaki postpartum dönemde kadınların cinsellikle ilgili konuşmaya, sorular sormaya ihtiyaçları vardır. Başta birinci basamak sağlık çalışanları olmak üzere tüm sağlık profesyonelleri, kadınlara bütüncül bakım vermeli, cinsel sağlık gereksinimlerini belirlemeli ve danışmanlık yapmalıdır.

DSÖ'nün tavsiyelerine göre erken çocukluk ve anne sağl1$\breve{g} ı n ı$ hedefleyen programlarda önemli sağlık hedefleri arasında cinsel sağlık eğitimi ve danışmanlığı yer almaktadır. $\mathrm{Bu}$ tavsiyeye göre, cinsel sağlık hizmetlerinin birinci basamak sağlık hizmetlerine entegrasyonu ve sağlık ekibinin eğitimi gerekmektedir. ${ }^{[11,32]} \mathrm{Bu}$ nedenle cinselliğin değerlendirilmesi, cinsel eğitim ve cinsel sağlık danışmanlığı rutin postpartum bakımın bir parçası olmalı ve bu konuya önem verilmelidir.

Cinsel sağlık danışmanlığı yapan/yapacak olan sağlık personelin, danışan birey ile cinselliği daha rahat konuşabilmek için bazı modeller kullanması önerilmektedir. Sadece cinselliği değerlendirme amacı taşıyan modeller; ALARM, Schover, Kaplan modelidir. Cinsel sorunların çözümünü amaçlayan modeller; PLISSIT ve ExPLISSIT'dir. Hem değerlendirme hem de çözüm önerisi getiren modeller ise ALLOW, BETTER ve PLEASURE modelidir (Tablo 1). ${ }^{[34]}$ 
Tablo 1. Cinsel danışmanlıkta kullanılan modeller

\begin{tabular}{|c|c|c|c|c|}
\hline & ALARM modeli & \multicolumn{2}{|c|}{ Kaplan modeli } & Schover modeli \\
\hline \multirow[t]{2}{*}{$\begin{array}{l}\text { Değerlendirme } \\
\text { amaçlı }\end{array}$} & $\begin{array}{l}\text { Ayrıntılı görüşme ile cinsel yanıt } \\
\text { döngüsünün her aşamasını } \\
\text { değerlendirerek meydana gelen } \\
\text { sorunları bulmayı amaçlamaktadır. } \\
\text { Karşılıklı etkileşime vurgu } \\
\text { yaparak sağlık profesyonellerine } \\
\text { derinlemesine öykü alma konusunda } \\
\text { rehberlik yapmaktadır. }\end{array}$ & \multicolumn{2}{|c|}{$\begin{array}{l}\text { Bu model, sağlık profesyonellerine } \\
\text { cinsel yanıt döngüsünde meydana } \\
\text { gelen sorunların belirlenmesi ve } \\
\text { öneri geliştirilmesi amacıyla rehberlik } \\
\text { etmek için geliştirilmiştir. Cinsel öykü } \\
\text { alma ve Özet-Öneriler olmak üzere iki } \\
\text { basamaktan oluşmaktadır. }\end{array}$} & $\begin{array}{l}\text { Schover tarafindan } 1998 \text { yılında } \\
\text { geliştirilen bu model, tedavi } \\
\text { amacı gözetmeksizin bireyin cinsel } \\
\text { öyküsünü değerlendirmek ve cinsel } \\
\text { sorunları belirlemek amacıyla } \\
\text { geliştirilmiştir. Bireyin geçmiş } \\
\text { cinsel yaşamına ve mevcut cinsel } \\
\text { yakınmalarına odaklanarak cinsel } \\
\text { yanıt döngüsünde meydana gelen } \\
\text { sorunları belirleyip danışmanlık } \\
\text { hedefleri oluşturmayı sağlar. }\end{array}$ \\
\hline & \multicolumn{2}{|l|}{ PLISSIT modeli } & \multicolumn{2}{|c|}{ Ex-PLISSIT modeli } \\
\hline \multirow[t]{2}{*}{ Çözüm amaçlı } & \multicolumn{2}{|c|}{$\begin{array}{l}1976 \text { yılında Annon tarafindan geliştirilmiştir. Cinsel öykü } \\
\text { alma ve cinselliğin değerlendirilmesiyle başlayıp bireye } \\
\text { özgü öneri ve tedavi planı ile sonlanan bir modeldir. } \\
\text { Sağlık profesyonelleri ile bireyler arasında iş birliği } \\
\text { yapılarak cinsel danışmanlık yöntemi ile mevcut cinsel } \\
\text { sorunların çözümü amaçlanmaktadır. }\end{array}$} & \multicolumn{2}{|c|}{$\begin{array}{c}\text { PLISSIT Modeli } 2006 \text { yılında Taylor ve Davis tarafindan } \\
\text { yenilenerek Ex-PLISSIT modeli geliştirilmiştir. Temel fark, } \\
\text { İzin Verme basamağının diğer basamakların merkezinde } \\
\text { olmasıdır. PLISSIT modelindeki gibi her bir basamak sırayla } \\
\text { değil birbiriyle iç içedir. Bu şekilde bireyin cinselliğe yönelik } \\
\text { duygu ve düşüncelerini ortaya koymayı sağlar. }\end{array}$} \\
\hline & ALLOW modeli & \multicolumn{2}{|c|}{ BETTER modeli } & PLEASURE modeli \\
\hline $\begin{array}{l}\text { Değerlendirme ve } \\
\text { çözüm amaçlı }\end{array}$ & $\begin{array}{l}\text { Bu model cinsel sağlığı } \\
\text { değerlendirmeyi ve cinsel } \\
\text { sorunlara yönelik çözüm önerilerini } \\
\text { içermektedir. Çözüm önerileri olarak } \\
\text { eğitim, danışmanlık ve cinsel tedavi } \\
\text { seçenekleri sunulmuştur. }\end{array}$ & \multicolumn{2}{|c|}{$\begin{array}{l}\text { Sağılık profesyonellere onkoloji } \\
\text { hastalarından cinsel öykü alma ve } \\
\text { cinselliği değerlendirme konusunda } \\
\text { rehberlik etmek amacıyla geliştirilmiştir. } \\
\text { Cinsel öykü alma sürecinde sağlık } \\
\text { profesyoneli ile birey arasındaki } \\
\text { iletişimi başlatmaya, cinsel sağlığı } \\
\text { değerlendirmeye ve sorunları } \\
\text { belirlemeye yardımcıdır. }\end{array}$} & $\begin{array}{l}\text { Bireyin cinsel öykü ve sorunlarını } \\
\text { belirlemeye ek olarak bireyin } \\
\text { cinselliğe yönelik duygu, düşünce, } \\
\text { mitleri, davranışlarını ve cinsel } \\
\text { doyum/memnuniyetlerini } \\
\text { belirlemeyi amaçlamıştı. }\end{array}$ \\
\hline
\end{tabular}

Torkzahrani ve ark.'nın (2016) emziren kadınlarda PLISSIT modeline dayalı danışmanlığın cinsel işleve etkisini değerlendirmek amacıyla yaptığı çalışmaya doğumdan sonraki ilk altı ayda emziren ve en az bir cinsel sorunu olan 90 kadın dahil edilmiştir. Bu çalışmanın sonucuna göre, emziren kadınların cinsel sorunları PLISSIT modeli kullanılarak azalmış ve postpartum bakımda PLISSIT modelinin kullanılması tavsiye edilmiştir. ${ }^{[35]}$

Doğum sonrası kadınların cinsel işlevi ve evlilik doyumu üzerindeki Ex-PLISSIT modeline dayalı danışmanlığın etkisini araştırmak amacıyla yapılan randomize kontrollü çalışmada (RKÇ) müdahale grubunda, Ex-PLISSIT modeline dayalı cinsel danışmanlığın doğum sonrası kadınların cinsel işlevini iyileştirebileceği ve evlilik memnuniyetini artırabileceği saptanmıştır. ${ }^{[36]}$

Postpartum dönemde yaşanan cinsel sorunların çözümünde PLISSIT modeline dayalı cinsel danışmanlıkta yaygın kullanılmaktadır. PLISSIT modeline dayalı cinsel danışmanlık ile yapılan iki çalışma sonucunda, kadınların cinsel sorunlarının azaldığı ve cinsel yaşam kalitesinin arttığı belirlenmiştir. ${ }^{[37,38]}$ Abdelhakm ve ark. (2018) yarı deneysel çalışmasında PLISSIT modeline dayalı cinsel danışmanlık almadan önce kadınların sadece \%13,6'sı iyi bir cinsel yaşam kalitesine sahip iken, danışmanlık sonrası bu oran $\% 44,5$ 'e yükselmiştir. ${ }^{[38]}$

Transteoretik modele dayalı interaktif doğum sonrası cinsel sağlık eğitimi programının doğum sonrası kadınların cinsel davranışlarını ve sağlığını geliştirmedeki etkinliğini değerlendirmek amacıyla Lee ve Tsai'nın (2012) yaptığı çalışmada katılımcılar üç gruba ayrılmıştır. Deney A grubuna teori tabanlı cinsel sağlık eğitimi verilmiş, deney B grubuna interaktif kendi kendine yardım broşürü verilmiş olup kontrol grubuna ise rutin eğitim (10-15 dakikalık eğitim konuşması ve interaktif olmayan broşür) verilmiştir. Çalışmada veriler başlangıçta, postpartum üçüncü gün, ikinci ve üçüncü ayda toplanmıştır. Çalışma sonucunda teori temelli cinsel sağlık eğitimi alan kadınların diğer gruplara göre cinsel öz-yeterliliği ve cinsel aktivite çeşitliliği daha yüksek ve anlamlı bulunmuştur. Aynı zamanda cinsel eğitim alan kadınların, rutin eğitim ve yalnızca interaktif broşür alan kadınlara göre cinsel yaşamlarına daha erken dönme eğiliminde oldukları saptanmıştır. Çalışma sonucunda transteoretik modele dayalı bir cinsel sağlık eğitim programının kadınların cinsel sağlığını ve cinsel davranışını iyileştirdiğini ve transteorik modelin, doğum sonrası cinsel sağlığı iyileştirmede kullanımını destekleyerek uygulamaya dönüştürülebileceği belirtilmiştir. ${ }^{[39]}$ 
Tablo 2. Derlemeye alınan araştırmaların özellikleri

\begin{tabular}{|c|c|c|c|c|c|c|c|}
\hline Yazar/Yıl/Ülke & Araştırma Tipi & Populasyon & Örneklem & Model & Müdahale & Veri toplama & Sonuçlar \\
\hline $\begin{array}{l}\text { Pardell- } \\
\text { Dominguez ve } \\
\text { ark. (2021), } \\
\text { İspanya }\end{array}$ & $\begin{array}{c}\text { Fenomenolojik } \\
\text { araştirma }\end{array}$ & $\begin{array}{l}\text { Primipar } \\
\text { Postpartum } \\
\text { kadınlar }\end{array}$ & 10 & - & - & $\begin{array}{c}\text { Yarı } \\
\text { yapılandırılmış } \\
\text { görüşme }\end{array}$ & $\begin{array}{l}\text { Beş ana tema: 'hazır } \\
\text { hissetmeme', 'engelleyici } \\
\text { faktörler', 'evde yeni } \\
\text { gerçeklik', 'sosyo-kültürel } \\
\text { faktörler' ve 'sağlık } \\
\text { sistemi içinde klinisyen' }\end{array}$ \\
\hline $\begin{array}{l}\text { De Souza ve } \\
\text { ark. (2015), } \\
\text { Avustralya }\end{array}$ & $\begin{array}{c}\text { Prospektif } \\
\text { kohort }\end{array}$ & $\begin{array}{l}\text { Gebeler- } \\
\text { Postpartum } \\
\text { kadınlar }\end{array}$ & 391 & - & - & FSFI & $\begin{array}{l}\text { Cinsel işlev, doğum } \\
\text { şekline ve perineal } \\
\text { yaralanma varlığı } \\
\text { farketmeksizin } \\
\text { postpartum 12. Ayda } \\
\text { erken gebelik dönemine } \\
\text { dönmektedir. }\end{array}$ \\
\hline $\begin{array}{l}\text { Alp-Yılmaz ve } \\
\text { ark. (2019), } \\
\text { Türkiye }\end{array}$ & $\begin{array}{c}\text { Kesitsel ve } \\
\text { karşılaştırmalı }\end{array}$ & $\begin{array}{l}\text { Emziren ve } \\
\text { emzirmeyen } \\
\text { postpartum } \\
\text { kadınlar }\end{array}$ & $\begin{array}{c}337 \\
\text { (Emziren: } \\
161, \\
\text { Emzirmeyen: } \\
176)\end{array}$ & - & - & СYKÖ-К & $\begin{array}{l}\text { Emziren grupta daha } \\
\text { düşük cinsel istek ve } \\
\text { cinsel ilişki sıklığının } \\
\text { az olmasına rağmen, } \\
\text { bildirilen cinsel yaşam } \\
\text { kalitesi emziren ve } \\
\text { emzirmeyen kadınlarda } \\
\text { benzer bulunmuştur }\end{array}$ \\
\hline $\begin{array}{l}\text { Sheikhi ve ark. } \\
\text { (2020), İran }\end{array}$ & RKÇ & $\begin{array}{l}\text { Primipar } \\
\text { postpartum } \\
\text { kadınlar }\end{array}$ & $\begin{array}{l}94 \\
\text { (Girişim: 47, } \\
\text { Kontrol: 47) }\end{array}$ & - & $\begin{array}{l}\text { Cinsel sağlık } \\
\text { eğitimi }\end{array}$ & FSFI & $\begin{array}{l}\text { Doğum sonrası dönemde } \\
\text { cinsel sağlık eğitimi } \\
\text { kadınlarda cinsel işlevi } \\
\text { iyileştirmiştir. }\end{array}$ \\
\hline $\begin{array}{l}\text { Rahimi ve ark. } \\
(2020), \\
\text { İran }\end{array}$ & Deneysel & $\begin{array}{l}\text { Nullipar } \\
\text { gebeler }\end{array}$ & 150 & - & $\begin{array}{l}\text { Cinsellik, cinsel } \\
\text { sağlık, PTKE } \\
\text { eğitim paketi }\end{array}$ & $\begin{array}{l}\text { ENRICH Evlilik } \\
\text { Doyumu Ölçeği }\end{array}$ & $\begin{array}{l}\text { Doğum öncesi verilen } \\
\text { bir eğitim paketi ile } \\
\text { kadınlarda doğum sonrası } \\
\text { evlilik memnuniyetinin } \\
\text { arttrılabileceği } \\
\text { gösterilmiştir }\end{array}$ \\
\hline $\begin{array}{l}\text { Lee ve Tsai } \\
\text { (2012), Tayvan }\end{array}$ & Prospektif RKÇ & $\begin{array}{l}\text { Postpartum } \\
\text { kadınlar }\end{array}$ & 250 & $\begin{array}{c}\text { TT } \\
\text { Model }\end{array}$ & $\begin{array}{l}\text { İnteraktif doğum } \\
\text { sonrası cinsel } \\
\text { sağlık eğitimi }\end{array}$ & - & $\begin{array}{l}\text { Teoriye dayalı bir doğum } \\
\text { sonrası cinsel sağlık } \\
\text { eğitimi programının } \\
\text { kadınların cinsel sağlığını } \\
\text { ve cinsel davranışını } \\
\text { iyileştirdiğini ve trans } \\
\text { teorik modelin, doğum } \\
\text { sonrası kadınların cinsel } \\
\text { sağlığını iyileştirmek için } \\
\text { kullanımını destekleyerek } \\
\text { uygulamaya } \\
\text { dönüştürülebileceğini } \\
\text { belirtilmiştir. }\end{array}$ \\
\hline $\begin{array}{l}\text { Torkzahrani } \\
\text { ve ark. (2016), } \\
\text { İran }\end{array}$ & RKÇ & $\begin{array}{c}\text { Doğumdan } \\
\text { sonraki ilk altı } \\
\text { ayda emziren } \\
\text { ve en az bir } \\
\text { cinsel sorunu } \\
\text { kadınlar }\end{array}$ & 90 & $\begin{array}{l}\text { PLISSIT } \\
\text { modeli }\end{array}$ & $\begin{array}{c}\text { Cinsel } \\
\text { danışmanlık }\end{array}$ & FSFI & $\begin{array}{l}\text { Emziren kadınların cinsel } \\
\text { sorunları PLISSIT modeli } \\
\text { kullanılarak azalmıştır } \\
\text { ve postpartum bakımda } \\
\text { PLISSIT modelinin } \\
\text { kullanılması tavsiye } \\
\text { edilmiştir }\end{array}$ \\
\hline $\begin{array}{l}\text { Malakouti ve } \\
\text { ark. (2020), } \\
\text { İran }\end{array}$ & RKÇ & $\begin{array}{l}\text { Postpartum } \\
\text { kadınlar }\end{array}$ & 68 & $\begin{array}{c}\text { Ex- } \\
\text { PLISSIT }\end{array}$ & $\begin{array}{c}\text { Cinsel } \\
\text { danışmanlık }\end{array}$ & $\begin{array}{c}\text { FSFI, } \\
\text { ENRICH } \\
\text { Evlilik Doyumu } \\
\text { Ölçeği }\end{array}$ & $\begin{array}{l}\text { Ex-PLISSIT modeline } \\
\text { dayalı cinsel } \\
\text { danışmanlığın doğum } \\
\text { sonrası kadınların cinsel } \\
\text { işlevini iyileştirebileceğini } \\
\text { ve evlilik memnuniyetini } \\
\text { artırabileceğini } \\
\text { saptanmıştır }\end{array}$ \\
\hline
\end{tabular}


Tablo 2 devamı. Derlemeye alınan araştırmaların özellikleri

\begin{tabular}{|c|c|c|c|c|c|c|c|}
\hline Yazar/Yıl/Ülke & Araştırma Tipi & Populasyon & Örneklem & Model & Müdahale & Veri toplama & Sonuçlar \\
\hline $\begin{array}{l}\text { Abdelhakm ve } \\
\text { ark. (2018), } \\
\text { Mısır }\end{array}$ & Yarı deneysel & $\begin{array}{c}\text { Postpartum } \\
\text { kadınlar (ilk } \\
6 \text { ay) }\end{array}$ & 110 & $\begin{array}{l}\text { PLISSIT } \\
\text { modeli }\end{array}$ & $\begin{array}{c}\text { Cinsel } \\
\text { danışmanlık }\end{array}$ & $\begin{array}{c}\text { Görüşme anketi. } \\
\text { Arizona Cinsel } \\
\text { Deneyim Ölçeği } \\
\text { CYKÖ-K }\end{array}$ & $\begin{array}{l}\text { PLISSIT modeline dayalı } \\
\text { cinsel danışmanlık } \\
\text { programının kadınların } \\
\text { cinsel yaşam kalitesinin } \\
\text { iyileştirilmesi üzerinde } \\
\text { önemli bir etkisi olduğu } \\
\text { saptanmıştır }\end{array}$ \\
\hline $\begin{array}{l}\text { Yörük ve } \\
\text { Karaçam } \\
\text { (2016); Türkiye }\end{array}$ & Yarı deneysel & $\begin{array}{c}\text { Doğum } \\
\text { sonrası 3-12. } \\
\text { Arası kadınlar }\end{array}$ & 123 & $\begin{array}{l}\text { PLISSIT } \\
\text { modeli }\end{array}$ & $\begin{array}{c}\text { Cinsel } \\
\text { danışmanlık }\end{array}$ & $\begin{array}{l}\text { Arizona Cinsel } \\
\text { Deneyim Ölçeği } \\
\text { CYKÖ-K }\end{array}$ & $\begin{array}{l}\text { PLISSIT modeline dayalı } \\
\text { cinsel danışmanlığın } \\
\text { kadınların yaşadığı doğum } \\
\text { sonrası cinsel sorunları } \\
\text { azalttığı ortaya çıkmıştır }\end{array}$ \\
\hline $\begin{array}{l}\text { Karimi ve ark. } \\
\text { (2021), Iran }\end{array}$ & RKÇ & $\begin{array}{c}\text { Doğum } \\
\text { sonrası 1-6 ay } \\
\text { arasında cinsel } \\
\text { sorunu olan } \\
\text { kadınlar } \\
\end{array}$ & 80 & $\begin{array}{l}\text { PLISSIT ve } \\
\text { BETTER } \\
\text { modeli }\end{array}$ & $\begin{array}{c}\text { Cinsel } \\
\text { danışmanlık }\end{array}$ & FSFI & $\begin{array}{l}\text { BETTER modeline dayalı } \\
\text { danışmanlık modelinin } \\
\text { doğum sonrası cinsel olarak } \\
\text { kendini ifade etmede daha } \\
\text { etkili olduğu bulunmuştur. }\end{array}$ \\
\hline $\begin{array}{l}\text { Evcili ve ark. } \\
\text { (2020), Türkiye }\end{array}$ & Deneysel & $\begin{array}{l}\text { Postpartum } \\
\text { kadınlar }\end{array}$ & 67 & $\begin{array}{l}\text { Levine'nin } \\
\text { koruma } \\
\text { modeli }\end{array}$ & $\begin{array}{l}\text { Cinsel sağlık } \\
\text { eğitimi }\end{array}$ & $\begin{array}{l}\text { Kişisel bilgi formu, } \\
\text { FSFI, Arizona Cinsel } \\
\text { Deneyim Ölçeği } \\
\text { ve Golombok-Rust } \\
\text { Cinsel Doyum } \\
\text { Envanteri }\end{array}$ & $\begin{array}{l}\text { Levine'nin koruma } \\
\text { modeline göre } \\
\text { yapılandırılmış bir doğum } \\
\text { sonrası cinsel sağlık } \\
\text { eğitiminin doğum sonrası } \\
\text { kadınların cinsel işlevlerini } \\
\text { ve memnuniyetini } \\
\text { artırmada etkili olduğu } \\
\text { bulunmuştur. }\end{array}$ \\
\hline $\begin{array}{l}\text { Aghababaei } \\
\text { ve ark. (2020), } \\
\text { İran }\end{array}$ & Yarı-deneysel & $\begin{array}{l}\text { Doğum } \\
\text { sonrası 2-6 } \\
\text { ay arası olan } \\
\text { kadınlar }\end{array}$ & 104 & $\begin{array}{l}\text { REDI } \\
\text { modeli }\end{array}$ & $\begin{array}{c}\text { Cinsel } \\
\text { danışmanlık }\end{array}$ & $\begin{array}{c}\text { Kişisel bilgi formu, } \\
\text { FSFI }\end{array}$ & $\begin{array}{l}\text { Cinsel istekleri azalmış } \\
\text { emziren kadınların REDı } \\
\text { modeline dayalı cinsel } \\
\text { danışmanlık yoluyla } \\
\text { desteklenmesinin cinsel } \\
\text { işlevlerinde önemli bir } \\
\text { fark yaratabileceğini } \\
\text { saptanmıştır }\end{array}$ \\
\hline $\begin{array}{l}\text { Barghamadi } \\
\text { ve ark. (2020), } \\
\text { İran }\end{array}$ & RKÇ & $\begin{array}{l}\text { Doğum } \\
\text { sonrası 6-12 } \\
\text { ay emziren } \\
\text { kadınlar }\end{array}$ & 76 & - & $\begin{array}{c}\text { Kulak } \\
\text { akupresürü }\end{array}$ & $\begin{array}{c}\text { FSFI, } \\
\text { CYKÖ-K }\end{array}$ & $\begin{array}{l}\text { Emziren kadınlarda } \\
\text { kulak akupresürünün } \\
\text { cinsel işlev üzerindeki } \\
\text { etkisini desteklemesi } \\
\text { beklenmektedir. } \\
\text { Protokolün sonuçları } \\
\text { daha yayınlanmamıştır }\end{array}$ \\
\hline
\end{tabular}

Levine'nin koruma modeline göre yapılandırılmış bir doğum sonrası cinsel sağlık eğitimi programının doğum sonrası kadınlar üzerindeki etkilerinin belirlenmesi amacıyla Evcili ve ark. (2020) tarafından yapılan çalışmaya 67 kadın dahil edilmiştir. Müdahale grubuna, Levine'nin koruma modeline göre yapılandırılmış doğum sonrası cinsel sağı̆ı eğitimi programı verilirken, kontrol grubu rutin taburculuk eğitimi almıştır. Çalışmanın sonucunda verilen cinsel eğitim programının, doğum sonrası kadınların cinsel işlevlerini ve memnuniyetini artırmada etkili olduğu bulunmuştur. ${ }^{[40]}$

Aghababaei ve ark.'nın (2020) cinsel isteği azalmış emziren kadınlarda REDI (rapport building, exploration, decision making, and implementing the decision) modeline dayalı danışmanlığın cinsel işlev üzerine etkisini belirlemek amacıyla yaptıkları çalışmaya 104 kadın dahil edilmiştir. Çalışmaya doğum sonrası 2-6 ay arasında ve cinsel istek bozukluğu olan kadınlar alınmıştır. Danışmanlık seansları, REDI modeline dayalı olarak haftada bir 45-90 dakikalık seans olmak üzere dört seanstan oluşmaktadır. Bu çalışmanın sonucunda cinsel istekleri azalmış emziren kadınların REDI modeline dayalı cinsel danışmanlık yoluyla desteklenmesinin cinsel işlevlerinde önemli bir fark yaratabileceği saptanmıştır. ${ }^{[41]}$

Literatürde postpartum dönemde cinselliğin değerlendirilmesinde yaygın olarak PLISSIT modeli kullanıldığı görülmüştür. ${ }^{[37,38,42-46]}$ Doğum sonrası cinsel sorunların 
ifade edilmesinde PLISSIT ve BETTER modeline dayalı danışmanlığın etkisini karşılaştıran Karimi ve ark.'nın (2021) yaptığı çalışmaya doğum sonrası dört hafta ile altı ay arasında cinsel sorunu olan 80 kadın dahil edilmiştir. Girişimler 60-90 dakikalık iki seans şeklinde olmuştur. Her iki grupta cinsellik, girişim öncesi ve sonrası Kadın Cinsel İşlev Endeksi ile değerlendirilmiştir. Çalışmanın sonucunda BETTER modeline dayalı danışmanlık modelinin doğum sonrası cinsel olarak kendini ifade etmede PLISSIT modeline göre daha etkili olduğu bulunmuştur. ${ }^{[4]}$

\section{BETTER MODELI i ILE CINSEL DANIȘMANLIK}

Sağlık profesyonellerine onkoloji hastalarından cinsel öykü alma ve cinselliği değerlendirme konusunda rehberlik etmek amacıyla BETTER modeli geliştirilmiştir. ${ }^{[34]} \mathrm{Bu}$ model kullanımı, hasta bireyler ile cinsellik hakkında konuşurken klinisyenlere fayda sağlamaktadır. Aynı zamanda klinisyenlere diyabet, kardiyovasküler hastalık gibi tıbbi durumlardan kaynaklanan cinsellik sorunlarını değerlendirmek ve çözmek için bir çerçeve sunmaktadır. BETTER modeli basit, iletişimi geliştiren, hemşirelerin cinsellik konusunu tanıtmalarına yardımcı olan ve "kişi merkezli yaklaşım” 1 kolaylaştıran bir modeldir. ${ }^{[48]}$

BETTER modeli, Bring up (Getir), Explain (Açıla), Tell (Anlat), Time (Zamanlama), Educate (Eğit) ve Record (Kaydet) olmak üzere altı basamaktan oluşur. ${ }^{\text {[7,49-51] }}$

1- Bring up/Konuyu gündeme getirmek: Hemşire, postpartum dönemdeki kadını cinsel sorunlarını rahatlıkla gündeme getirmesi ve konuşması için teşvik etmelidir. Hemşire konuyu gündeme getirdiğinde, kadın yanıt vermemeyi seçse bile, hemşire her zaman dinlemeye açık olduğunu bildirmeli ve daha sonraki bir tarihte görüşmek isterse bu konuları tartışmaya hazır olduğunu belirtmelidir. Hemşire kadına doğum sonrası eşi ile yakınlığı ve ilişkisi hakkında soru sorarak konuyu gündeme getirmiş olmaktadir. ${ }^{[49,52]}$

\section{Örnĕgin:}

Hemşire (B): 'Zehra Hanım eğer biraz zamanınız varsa sizinle konuşmak isterim'

Zehra Hanım (Z): 'Tabii, ne hakkında'

B: 'Doğum sonrası dönem bir uyum dönemidir aslında. Hem yeni yaşamımıza uyum sağlama hem de eski düzenimize geri dönme dönemidir. Vücudumuz, hormonlarımız ve cinsel yaşantımız gebelik öncesi dönemine yavaş yavaş dönecektir. Mesela sizin doğum sonrası bu bir aylık süreçte eşiniz ile ilişkiniz, yakınlığınız nasıl?’
Z: 'Bu konuyu konuşmasak...'

B: 'Sizi sıkmak istemem tabi. Siz ne zaman konuşmak isterseniz o zaman konuşalım. Ben siz kontrole gelmişken konuşmak istedim, istediğiniz her zaman konuşabiliriz sizinle bu konuyu'

Z: 'Hı..., iyiiii, yani olması gerektiği gibi. İyiii iyiii...

2- Explain/Açıklama: Hemşire, cinsel sorunların bireyin yaşam kalitesi üzerindeki önemini ve etkisini açıklar. Bu, tartışmayı normalleştirmeye yardımcı olur ve hastaların daha az utanç ve daha az yalnız hissetmelerini sağlayacaktır. Danışan kişiye cinselliğin yaşamın bir parçası olduğu söylenmelidir. ${ }^{[49,52]}$

B: 'Zehra Hanım doğum sonrası dönemde biz kadınların vücudunda birçok fizyolojik, anatomik ve hormonal değişimler olmaktadır. Bu değişimler nedeniyle doğum sonrası dönemde bazı sorunlar yaşayabiliriz. Bu sorunlardan bir tanesi cinsel sorunlar olabilir. Lütfen bu sorunu küçümsemeyelim ya da yok saymayalım. Çünkü cinsel sağlık bireyin genel sağlığının bir parçasıdır. O nedenle cinsel yaşamı sağlıklı, iyi olmayan birinin yaşam kalitesi de iyi olmuyor maalesef. Örneğin: kendinizi depresyonda hissettiğiniz günler keyif verici, kaliteli oluyor mu?. Mental sağlık yaşam kalitenizi nasıl etkiliyorsa cinsel sağlık da o derece etkilemektedir, unutmayın lütfen.’

Z: 'hı1 anladımm. Yok unutmam.'

3- Tell/Anlat: Hemşire, danışana sorunlarının çözümü için eksiksiz bilgi sağlanması konusunda güvence verir. Bu basamak, hemşirenin danışana, endişelerine acil bir çözüm şu anda mevcut olmasa bile, yardımcı olmak için uzman bir servise yönlendireceğini söylediği basamaktır. ${ }^{[49,52]}$

B: Doğum sonrası çoğu kadın cinsel problemler yaşamaktadır. Aslında bu sorunların basit ve etkili çözümleri vardır. Aslında bizler gözümüzde büyütüyoruz. O nedenle siz de yaşadığınız bir problem varsa paylaşırsanız size gereken tüm bilgileri ve çözüm yollarını anlatabilirim, siz de size uygun yöntemi seçebilirsiniz Zehra Hanım.'

Z: Pekii o zaman. Biz eşimle evlendikten yaklaşık iki üç ay sonra gebe olduğumu öğrendim. Yani tamam öncesince flört döneminde birbirimizi tanıyorduk ama evli olarak birbirimizi çok tanıma fırsatımız olmadı. Bir de nasıl söylesem cinselliği de çok yaşayamadık gebelik nedeniyle. Evlendik, hemen gebe kaldım. Gebelikte de zarar gelir diye cinsel ilişkiye giremedik, bir ya da iki kere. Şu anda ne yapacağımı bilmiyorum, bu süreçte eşim acaba istiyor mu istemiyor mu bilmiyorum, soramıyorum ya da cinselliği ben teklif edemiyorum. Açıkçası korkum da var. İlişki 
sırasında ağrım olur mu diye, çünkü dikişlerim var. Öte yandan, inanın o kadar da yorgunum ki... Hem daha kırkım çıkmadı...

4- Time/Zamanlama: Hemşire, danışmanlık süresini danışanın tercihine göre belirler. Cinsel sorunlarla uğraşmaya hazır olmayan danışanlar ileride bilgi isteyebilir. ${ }^{[49,52]}$

B: Sizi çok iyi anlıyorum. Eğer biraz daha zamanınız varsa size neler yapabileceğinizden bahsetmek isterim. Ĕger zamanım yok derseniz sizin uygun olduğunuz bir zamanda randevu oluşturalım?

Z: Aslında biraz zamanım var dinleyebilirim sizi.

5- Educate/Eğitim: Hemşire, danışanların gereksinimi olan eğitimleri belirleyip eğitimleri uygulamalıdır. Eğer varsa tedavilerin cinsel yan etkileri konusunda eğitmelidir. Danışanları cinsel yan etkiler hakkında bilgilendirmek, diğer olumsuz etkiler hakkında bilgilendirmek kadar önemlidir. ${ }^{[49,52]}$

B: Çok sevindim. Öncelikle eşiniz ile iletişim halinde olmanız ve iletişiminizin güçlü olması önemlidir. Evet daha yeni evlisiniz ve cinsel anlamda iletişim konusunda birbirinizi tanımıyor olabilirsiniz. Fakat cinselliği kadın başlatmaz gibi cinsellikle ilgili yanlış inanışları unutmanızı istiyorum. Çünkü bunlar yanlıştır. Cinselliği kadında erkek de başlatabilir. Ayrıca cinselliğe başlamak için kendinizi hazır hissetmeniz çok önemlidir. Doğum sonrası dönemde bazı kadınlar kuruluk yaşayabilir ve bundan dolayı cinsel ilişki sırasında ağrı yaşayabilir. Bunun için size kayganlaştırıcıları önerebilirim. Ayrıca önemli bir eğitim olan kegel egzersizlerini de önermek ve anlatmak isterim size. (Kegel egzersizleri anlatıldı ve danışan ile uygulandı).

Z: Çok teşekkür ederim Betül hemşire, iyi ki gelmişim bugün buraya çok güzel bir sohbetti ve çok şey öğrendim sayende. Görüşmek üzere.

6- Record/Kayıt: Değerlendirmeler, müdahaleler ve terapötik sonuçlar hemşire tarafından kaydedilir. ${ }^{[49,52]}$

B: Görüşürüz. (Betül hemşire Zehra Hanım ile yaptığı görüşmeyi tarih, saat ve konu belirterek kayıt altına alır).

\section{SONUCC}

Postpartum cinsel sağlık, kadınlar için çok yönlü bir endişe kaynağıdır. Cinsel sağlığın genel sağlığın bir bileşeni olduğu düşünürsek, kadının sağlıklı ve mutlu olması için cinsel yaşamının da değerlendirilmesi, sorunların ve çözümlerin belirlenmesi gerekmektedir. Postpartum cinsel sağlığın değerlendirilmesinde ve iyileştirilmesinde PLISSIT, BETTER, REDI, Levine modellerine dayalı cinsel sağlık eğitimlerin ve danışmanlıkların etkili olduğu görülmektedir. Modele dayalı cinsel eğitim ve danışmanlık alan kadınlarda cinsel sorunlarının azaldığı, cinsel yaşam kalitesinin arttığı ve cinsel yaşamlarının daha erken başladığı, ayrıca stres, kaygı ve depresyonu azaldığı görülmüştür. Bu nedenle sağlık profesyonelleri postpartum bakımda bu modellerinden birini kullanarak kadınların cinselliğini değerlendirmeli ve danışmanlık vermelidir. Yapılan son çalışmada BETTER modelinin PLISSIT modeline kıyasla daha etkili olduğu bulunmuştur. Bu sonuca dayanarak da BETTER modeline dayalı danışmanlığın kullanımının arttırılması ve bu konu ile ilgili daha fazla araştırma yapılması önerilmektedir.

\section{Hakem Değerlendirmesi}

Dış bağımsız.

Çıkar Çatışmas

Yazarlar çıkar ilişkisi olmadığını beyan etmişlerdir.

Finansal Destek

Herhangi bir mali destek alınmamıştır.

\section{Peer-review}

Externally peer-reviewed.

Conflict of Interest

No conflict of interest was declared by the authors.

Financial Disclosure

No financial support has been received.

\section{KAYNAKLAR}

1. Ventriglio A, Bhugra D. Sexuality in the 21st century: sexual fluidity. East Asian Arch Psychiatry 2019;29:30-4. [CrossRef]

2. Koç E, Oskay Ü. Postpartum dönemde cinsellik ve Danışmanlık. KASHED 2015;2:15-26. https://dergipark.org.tr/tr/download/ article-file/207495

3. Topuz Ş, Gönenç İM. Doğum Sonu Dönem ve Cinsel Sağlık. İstanbul: Nobel tıp Kitabevleri; 2019. p.197-202.

4. World Health Organization. Sexual Health 2002. Available from: http://www.who.int/reproductive-health/gender/sexualhealth. html

5. Mete S. Kadın ve Cinsellik. İstanbul: Nobel Tıp Kitabevleri; 2015. p.38-46.

6. Jawed-Wessel S, Sevick E. The impact of pregnancy and childbirth on sexual behaviors: A systematic review. J Sex Res 2017;54:41123. [CrossRef]

7. Henderson A, Harmon S, Newman H. The price mothers pay, even when they are not buying it: Mental health consequences of idealized motherhood. Sex Roles 2016;74:512-26. [CrossRef]

8. Jawed-Wessel WS, Wessel SD, Herbenick VS. The relationship between body image, female genital self-image and sexual function among first time mothers. J Sex Marital Ther 2016;43:618-32. [CrossRef]

9. McDonald EA, Gartland D, Small R, Brown SJ. Dyspareunia and childbirth: a prospective cohort study. BJOG 2015;122:672-9. [CrossRef]

10. Traumer L, Jacobsen MH, Laursen BS. Patients' experiences of sexuality as a taboo subject in the Danish healthcare system: a qualitative interview study. Scand J Caring Sci 2019;33:57-66. [CrossRef] 
11. World Health Organization. WHO recommendations on Postnatal care of the mother and newborn: A Practical Guide 2013 p.1-72. https://apps.who.int/iris/ bitstream/handle/10665/97603/9789241506649_eng. pdf? sequence $=1$ \&isAllowed $=y$

12. Leeman LM, Rogers R, Borders N, Teaf D, Qualls C. The effect of perineal lacerations on pelvic floor function and anatomy at 6 months postpartum in a prospective cohort of nulliparous women. Birth 2016;43:293-302. [CrossRef]

13. Martínez-Martínez A, Arnau J, Salmerón JA, Velandrino AP, Martínez ME. The sexual function of women during puerperium: a qualitative study. Sex Relat Ther 2017;32:181-94. [CrossRef]

14. Gutzeit O, Levy G, Lowenstein L. Postpartum Female Sexual Function: Risk Factors for Postpartum Sexual Dysfunction. Sex Med 2020;8:8-13. [CrossRef]

15. Alp Yilmaz F, Avci D, Arzu Aba Y, Ozdilek R, Dutucu N. Sexual Dysfunction in Postpartum Turkish Women: It's Relationship with Depression and Some Risk Factors. Afr J Reprod Health 2018;22:54-63. [CrossRef]

16. Pardell-Dominguez L, Palmieri PA, Dominguez-Cancino KA, Camacho-Rodriguez DE, Edwards JE, Watson J, Leyva-Moral JM. The meaning of postpartum sexual health for women living in Spain: a phenomenological inquiry. BMC Pregnancy Childbirth 2021;21:92. [CrossRef]

17. Cantarino SG, Pinto JMDM, Fabião JAdSAdO, García, AMC, Abellán MV, Rodrigues MA. The importance of religiosity/ spirituality in the sexuality of pregnant and postpartum women. PloS One 2016;11:e0156809. [CrossRef]

18. Gölbaşı Z, Eğri G. Doğum sonu dönemde annenin bakımına yönelik yapılan geleneksel uygulamalar. Cumhuriyet Med J 2010;32:276-82. https://dergipark.org.tr/en/download/articlefile/47626

19. Hacettepe Üniversitesi Nüfus Etütleri Enstitüsü. Türkiye Nüfus ve Sağlık Araştırması. Ankara: T. C. Kalkınma Bakanlığı ve TÜBİTAK; 2019. http://www.hips.hacettepe.edu.tr/tnsa2018/ rapor/TNSA2018_ana_Rapor.pdf

20. Cappell J, MacDonald TK, Pukall CF. For new mothers, the relationship matters: relationship characteristics and postpartum sexuality. Can J Hum Sex 2016;25:126-37. [CrossRef]

21. Fodstad K, Staff AC. Laine K. Sexual activity and dyspareunia the first year postpartum in relation to degree of perineal trauma. Int Urogynecol J 2016;27:1513-23. [CrossRef]

22. Triviño-Juárez JM, Romero-Ayuso D, Nieto-Pereda B, Forjaz MJ, Oliver-Barrecheguren C, Mellizo-Díaz S, et al. Resumption of intercourse, self-reported decline in sexual intercourse and dyspareunia in women by mode of birth: a prospective follow-up study. J Adv Nurs 2018;74:637-50. [CrossRef]

23. Colson M-H. Sexualité féminine et étapes de la parentalité. Gynecol Obstet Fertil 2014;42:714-20. [CrossRef]

24. Woolhouse H, McDonald E, Brown S. Women's experiences of sex and intimacy after childbirth: making the adjustment to motherhood. J Psychosom Obstet Gynecol 2012;33:185-90. [CrossRef]

25. O'Malley D, Higgins A, Smith V. Postpartum sexual health: a principle-based concept analysis. J Adv Nurs 2015;71:2247-57. [CrossRef]

26. O'Malley D, Smith V, Higgins A. Women's solutioning and strategising in relation to their postpartum sexual health: a qualitative study. Midwifery 2019;77:53-9. [CrossRef]

27. Navarro-Gil C, Gomez-Marińelarena C. Autoestima y autoimagen de las mujeres en el postparto. Med Nat 2016;10:30-5. https:// dialnet.unirioja.es/servlet/articulo?codigo $=5302216$
28. Aribi L, Ben Houidi A, Masmoudi R, Chaabane K, Guermazi M, Amami O. Female sexuality during pregnancy and postpartum: a study of 80 Tunisian women. La Tunisie Med 2012;90:873-7. http://www.latunisiemedicale.com/article-medicale-tunisie. php?article $=2095$

29. Enderle CF, Kerber NPC, Lunardi VL, Nobre CMG, Mattos L, Rodrigues EF. Constraints and/or determinants of return to sexual activity in the puerperium. Revista Latino-Americana de Enfermagem 2013;21:719-25. [CrossRef]

30. De Souza A, Dwyer PL, Charity M, Thomas E, Ferreira CH, Schierlitz L. The effects of mode delivery on postpartum sexual function: a prospective study. BJOG 2015;122:1410-8. [CrossRef]

31. Alp Yılmaz F, Şener Taplak A, Polat S. Breastfeeding and Sexual Activity and Sexual Quality in Postpartum Women. Breastfeed Med 2019;14:587-91. [CrossRef]

32. Sheikhi ZP, Navidian A, Rigi M. Effect of sexual health education on sexual function and resumption of sexual intercourse after childbirth in primiparous women. J Educ Health Promot 2020;9:87. [CrossRef]

33. Rahimi F, Goli S, Eslami F. The effect of educational classes during pregnancy on the level of sexual satisfaction after delivery in nulliparous women. J Educ Health Promot 2020;9:253. [CrossRef]

34. Büyükkayacı-Duman N. Cinselliğin Değerlendirilmesinde Model Kullanımı. İçinde: Büyükkayacı-Duman N. Cinsel Sağlık (Cinselliğin Fizyolojisi), editör. İstanbul: Nobel tıp Kitabevleri; 2019. p.59-65.

35. Torkzahrani S, Banaei M, Ozgoli G, Azad M, Mahmoudikohani F. The effectiveness of consultation based on plissit model on sexual function of lactating women. Nurs Midwifery J 2016;14:639-47. http://unmf.umsu.ac.ir/browse.php?a_id=2870\&sid=1 \&slc_ lang=en

36. Malakouti J, Golizadeh R, Mirghafourvand M, Farshbaf-Khalili A. The effect of counseling based on ex-PLISSIT model on sexual function and marital satisfaction of postpartum women: A randomized controlled clinical trial. Journal of education and health promotion 2020;9:284. [CrossRef]

37. Yörük F, Karaçam Z. The effectiveness of the PLISSIT model in solving postpartum sexual problems experienced by women. Athens J Health 2016;3:235-7. [CrossRef]

38. Abdelhakm EM, Said AR, Elsayed DMS. Effect of PLISSIT model sexual counseling program on sexual quality of life for postpartum women. Am J Nurs Sci 2018;7:63. [CrossRef]

39. Lee J-T, Tsai J-L. Transtheoretical model-based postpartum sexual health education program improves women's sexual behaviors and sexual health. J Sex Med 2012;9:986-96. [CrossRef]

40. Evcili F, Demirel G, Bekar M, Guler H. Effectiveness of postpartum sexual health education programme structured according to Levine's conservation model: An interventional study. Int J Nurs Pract 2020;26:e12855. [CrossRef]

41. Aghababaei S, Refaei M, Roshanaei G, Rouhani Mahmoodabadi SM., Heshmatian T. The Effect of Sexual Health Counseling Based on REDI Model on Sexual Function of Lactating Women with Decreased Sexual Desire. Breastfeed Med 2020;15:731-8. [CrossRef]

42. Abay H, Kaplan S. Histerektomi Sonrası Cinsel Sorunların Değerlendirilmesinde PLISSIT Modelinin Kullanılması. Int Ref J Nurs Res 2017;11:185-200. [Erişim]

43. Bennett MR. PLISSIT Interventions and Sexual Functioning: Useful Tools for Social Work in Palliative Care? J Social Work Endof-Life Palliative Care 2019;15:157-74. [CrossRef] 
44. Farnam F, Janghorbani M, Raisi F, Merghati-Khoei E. Compare the effectiveness of PLISSIT and sexual health models on Women's sexual problems in Tehran, Iran: a randomized controlled trial. J Sex Med 2014;11:2679-89. [CrossRef]

45. Tuğut N, Gölbaşı Z. Cinselliğinin Değerlendirilmesinde Plissit Modeli'nin Kullanımı. Gümüşhane Üniversitesi Sağlık Bilimleri Derg 2013;2:524-34. https://dergipark.org.tr/tr/download/ article-file/84260

46. Uslu E, İnfal S, Ulusoy MN. Cinsel sorunların çözümünde PLISSIT modelinin etkisi. Psikiyatride Güncel Yaklaşımlar 2016;8:52-63. [CrossRef]

47. Karimi F, Babazadeh R, Roudsari RL, Asgharipour N, Esmaily $\mathrm{H}$. Comparing the effectiveness of sexual counseling based on PLISSIT and BETTER models on sexual selfdisclosure in women with sexual problems after childbirth: A randomized trial. Iran J Nurs Midwifery Res 2021;26:68-74. [CrossRef]
48. Wright D, Pugnaire-Gros C. Let's talk about sex: Promoting staff dialogue on a mental health nursing unit. J Nurses Staff Dev 2010;26(6):250-5. [CrossRef]

49. Mick J, Hughes M, Cohen M. Using the BETTER model to assess sexuality. Clin J Oncol Nurs 2004;8:84-6. [CrossRef]

50. Quinn C, Happell B. Getting BETTER: Breaking the ice and warming to the inclusion of sexuality in mental health nursing care. Int J Ment Health Nurs 2012;21:154-62. [CrossRef]

51. Karakas S, Aslan E. Sexual counseling in women with primary infertility and sexual dysfunction: Use of the BETTER model. J Sex Marital Ther 2019;45:21-30. [CrossRef]

52. Ölçer Z, Oskay Ü. Kanser hastalarına yönelik BETTER modeline dayalı cinsel danışmanlık. Androl Bull 2020;22:177-82. [CrossRef] 